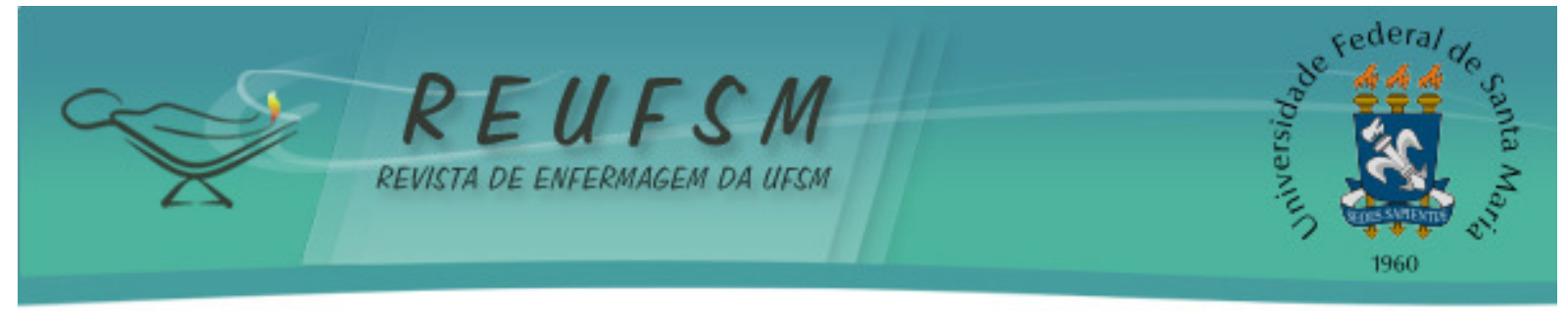

ARTIGO ORIGINAL

\title{
COTIDIANO DE ADOLESCENTES COM O VÍRUS DA IMUNODEFICIÊNCIA HUMANA EM TRATAMENTO
}

\author{
DAILY LIVING OF ADOLESCENTS WITH HUMAN IMMUNODEFICIENCY VIRUS UNDER \\ TREATMENT
}

\section{RUTINA DE ADOLESCENTES CON EL VIRUS DE LA INMUNODEFICIENCIA HUMANA EN EL TRATAMIENTO}

\author{
Cristiane Cardoso de Paula ${ }^{1}$ \\ Stela Maris de Mello Padoin ${ }^{2}$ \\ Paulo Victor Cesar de Albuquerque 3 \\ Renata de Moura Bubadué ${ }^{4}$ \\ Clarissa Bohrer da Silva ${ }^{5}$ \\ Crhis Netto de Brum ${ }^{6}$
}

Doi: $10.5902 / 217976929862$

RESUMO: Objetivo: descrever o cotidiano de adolescentes infectados pelo HIV em tratamento. Métodos: pesquisa qualitativa desenvolvida no primeiro semestre de 2012, em hospital de ensino na Região Sul do Brasil, com oito adolescentes na faixa etária de 13 a 19 anos. Os dados foram produzidos por meio da dinâmica de criatividade e sensibilidade denominada mapa falante. Para o tratamento dos dados, foi desenvolvida a análise de conteúdo. Resultados: emergiram quatro núcleos temáticos: da revolta à aceitação do diagnóstico e tratamento; entendimento dos motivos do tratamento; querer fazer o tratamento e receber ajuda; dificuldades de seguir a rotina de ingerir medicamento sempre, o dia todo e todos os dias. Conclusão: é importante conhecer o cotidiano vivenciado pelos adolescentes para desenvolver estratégias de educação em saúde e de apoio, promovidas pelo cuidado de enfermagem durante 0 acompanhamento interdisciplinar de saúde, vislumbrando a autonomia do adolescente para o cuidado de si. Descritores: Enfermagem; Saúde do adolescente; Síndrome da imunodeficiência adquirida; HIV; Adesão à medicação.

ABSTRACT: Aim: to describe the daily living of adolescents infected with HIV in treatment. Methods: qualitative research developed in the first semester of 2012, in a teaching hospital in the southern region of Brazil, with eight adolescents from 13 to 19 years old. Data were produced through Sensitivity and Creativity Dynamics called Talking Map. For data treatment, we developed content analysis. Results: four thematic nuclei emerged: from rebellion to acceptance of diagnosis and treatment; understanding the reasons for treatment; wanting to

\footnotetext{
${ }^{1}$ Enfermeira. Doutora em Enfermagem. Professora adjunta do Curso de Graduação e do Programa de PósGraduação em Enfermagem (PPGEnf) da Universidade Federal de Santa Maria (UFSM,RS,Brasil). Líder do Grupo de Pesquisa Cuidado à Saúde das Pessoas, Famílias e Sociedade (GP-PEFAS). E-mail: cris_depaula1@hotmail.com

${ }^{2}$ Enfermeira. Doutora em Enfermagem. Professora adjunta do Curso de Graduação e do PPGEnf UFSM. Líder do GP-PEFAS. E-mail: stelamaris_padoin@hotmail.com

${ }^{3}$ Acadêmico de Enfermagem da UFSM. Bolsista de Iniciação científica. Membro do GP-PEFAS. E-mail: victor.dealbuquerque@hotmail.com

${ }^{4}$ Enfermeira. Mestranda do Programa de Pós-graduação da Escola de Enfermagem Anna Nery (EEAN/UFRJ). Membro do GP-PEFAS. E-mail: renatabubadue@gmail.com

${ }^{5}$ Enfermeira. Mestranda do PPGEnf/UFSM. Membro do GP-PEFAS. E-mail: clabohrer@gmail.com

${ }^{6}$ Enfermeira. Mestre em Enfermagem. Doutoranda do Programa de Pós-graduação em Enfermagem da Universidade Federal do Rio Grande do Sul (PPGEnf/UFRGS). Membro do GP-PEFAS. E-mail: crhisdebrum@gmail.com
} 


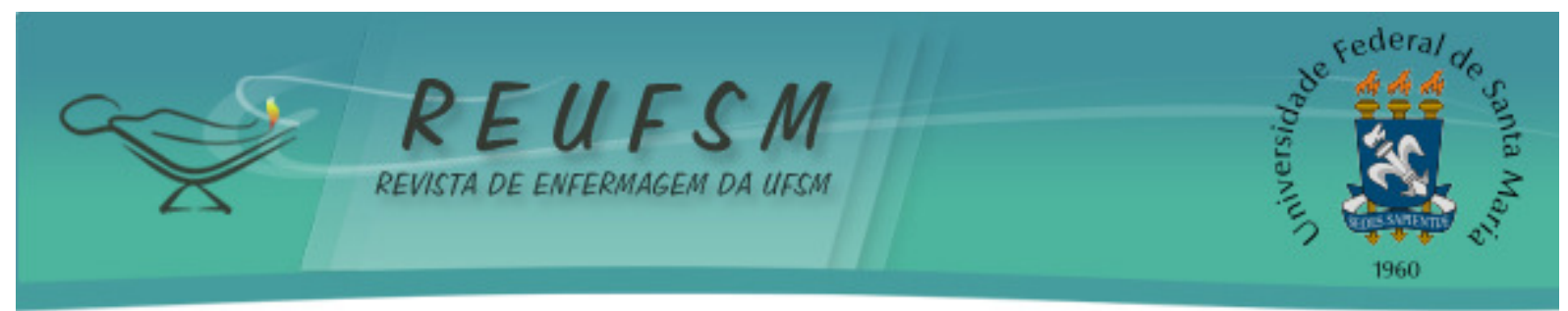

taking treatment and receiving help; difficulties of following the routine of ingesting medicine always, all day and every day. Conclusions: we concluded the importance of knowing the daily living through the adolescents to develop strategies of health and supporting education, promoted through nursing care during health interdisciplinary assistance glimpsing autonomy to the adolescents on caring for oneself.

Descriptors: Nursing; Adolescent health; Acquired immunodeficiency syndrome; HIV; Medication adherence.

RESUMÉN: Objetivo: describir la vida cotidiana de los adolescentes infectados por VIH en tratamiento. Métodos: investigación cualitativa desarrollada en 2012 en un hospital universitario en Brasil, con ocho adolescentes de edad entre 13 y 19 años. Los datos se obtuvieron a través de la dinámica de creatividad y sensibilidad llamada "mapa falante". Para el procesamiento de datos, se desarrolló un análisis de contenido. Resultados: surgieron cuatro núcleos temáticos: revuelta a la aceptación del diagnóstico y tratamiento, entendiendo de las razones del tratamiento; querer recibir el tratamiento y el apoyo, dificultades para seguir la rutina de ingerir medicación para siempre, todo el día y todos los días. Conclusión: es importante conocer el diario que viven los adolescentes para desarrollar estrategias de educación sanitaria y apoyo, promovidas por la atención de enfermería durante el acompañamiento interdisciplinario de salud, previendo la autonomía del adolescente para el cuidado de uno mismo.

Descriptores: Enfermería; Salud del adolescente; Síndrome de inmunodeficiencia adquirida; VIH; Cumplimiento de la medicación.

\section{INTRODUÇÃO}

A evolução da Síndrome da Imunodeficiência Adquirida (AIDS) no Brasil mostrou a tendência de juvenização da epidemia. De modo que, no período de 1980-2011, foram notificados 12.891 casos de infecção pelo vírus da imunodeficiência humana (HIV) na faixa etária de 13 a 19 anos de idade. ${ }^{\dagger}$ A mudança no perfil epidemiológico da doença implicou na formação de políticas públicas específicas e avanço do tratamento, que resultou na sobrevida e melhora na qualidade de vida dos adolescentes com HIV/AIDS. ${ }^{2}$

Além das demandas habituais de cuidado referentes ao processo de adolescer ${ }^{3}$, somam-se as demandas da especificidade da condição clínica decorrente da sorologia de infecção pelo HIV. Os adolescentes com HIV/AIDS são clinicamente frágeis; têm maior risco para apresentar condição crônica física, de desenvolvimento, comportamental ou emocional. Devido a esta fragilidade e cronicidade, requerem cuidados de saúde contínuos; necessitam de atendimento em saúde por uma equipe interdisciplinar; mantêm uso contínuo de medicamentos para sobreviver; precisam de serviços de suporte emocional; podem apresentar limitações de atividades; e carecem de ações de educação em saúde de forma contínua para promover a adesão ao tratamento. ${ }^{4}$

Diante desse panorama, destaca-se que o tratamento com terapia antirretroviral (TARV) repercute em benefícios às condições de saúde e que a adesão é determinante para o sucesso terapêutico, desacelerando o curso da doença. ${ }^{5}$ Entretanto, sabe-se dos desafios da adesão, como a apresentação dos medicamentos, a palatabilidade, a adaptação dos horários prescritos ao cotidiano, o ocultamento do diagnóstico, a necessidade de ajuda para manter o tratamento, entre outros. ${ }^{6}$

Sendo assim, a questão desta pesquisa foi: Como é o dia a dia dos adolescentes com HIV/AIDS no que se refere ao tratamento com terapia antirretrovital? E como objeto de estudo: o cotidiano medicamentoso dos adolescentes com HIV/AIDS. Assim, o objetivo deste estudo foi descrever o cotidiano medicamentoso de adolescentes em tratamento 


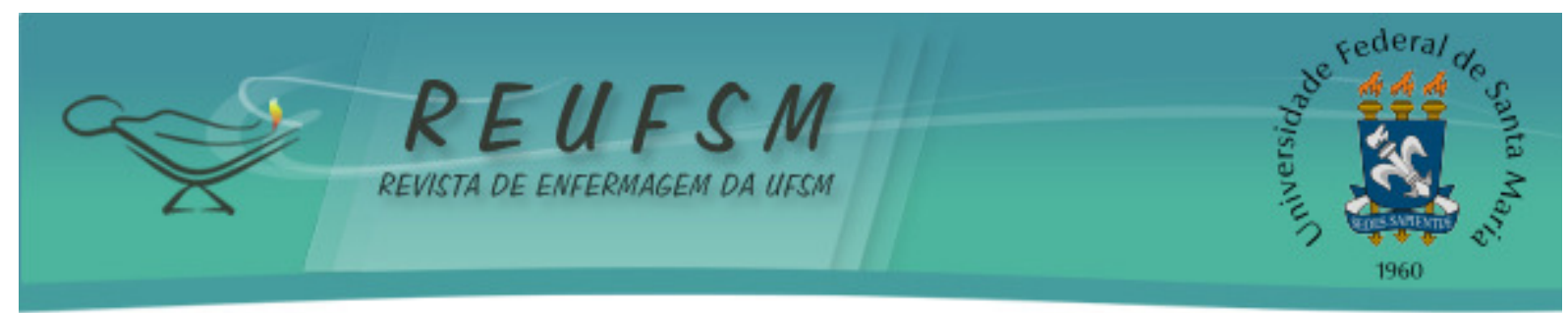

com TARV para o HIV, atendidos no serviço de referência do Município de Santa Maria/Rio Grande do Sul, Brasil.

\section{MÉTODO}

Trata-se de um estudo de abordagem qualitativa com aprovação no Comitê de Ética em Pesquisa da Universidade Federal de Santa Maria sob CAAE nº 0063.0.243.000-09, em julho de 2009. Corresponde a um subprojeto do projeto de pesquisa intitulado "Adolescentes HIV/AIDS: demandas da sua necessidade especial de saúde". Teve como cenário o Hospital Universitário de Santa Maria (HUSM), Santa Maria/Rio Grande do Sul (RS), sendo o serviço de referência da região centro-oeste do estado para o atendimento ambulatorial de crianças, adolescentes, adultos e gestantes com HIV/AIDS.

A etapa de campo foi desenvolvida no período de janeiro a junho de 2012, em dois encontros grupais, cada um com quatro adolescentes, totalizando oito sujeitos de pesquisa. Os critérios de inclusão: adolescentes com HIV/AIDS na faixa etária 13 a 19 anos, 11 meses e 29 dias, de acordo com critério etário estabelecido pelo Departamento de Doenças Sexualmente Transmissíveis (DST), AIDS e Hepatites Virais do Brasil; que tiveram a revelação diagnóstica; em tratamento antirretroviral e em acompanhamento no ambulatório. Os critérios de exclusão foram: apresentar limitação cognitiva e mental que dificultasse a expressão verbal. A seleção dos participantes se deu por meio de convite na sala de espera do ambulatório pediátrico do HUSM.

A pesquisa seguiu os preceitos éticos previstos na Resolução 196/96, a qual norteia o desenvolvimento de pesquisas com seres humanos. ${ }^{7}$ De maneira que os responsáveis assinaram o Termo de Consentimento Livre e Esclarecido e os oito adolescentes assinaram o Termo de Assentimento, anteriormente à produção dos dados. Para garantir o anonimato, foram adotados como códigos a letra A, referente à "adolescente", e um numeral em ordem crescente (A1, A2, sucessivamente).

A produção dos dados foi realizada por meio da Dinâmica de Criatividade e Sensibilidade (DCS) intitulada Mapa Falante. A DCS propõe um espaço de discussão coletiva, em que a experiência vivenciada é abordada por meio de uma produção artística (PA). ${ }^{8}$ A utilização da dinâmica Mapa Falante, nos dois encontros grupais, possibilitou a construção de um mapa desenhado pelos participantes, a fim de descrever o itinerário terapêutico de adolescentes soropositivos em TARV.

A operacionalização das DCS foi subdivida em cinco momentos: 1) realizou-se a apresentação do grupo, duplas foram formadas e após cinco minutos de conversa cada parceiro da dupla apresentou o outro; 2) foram apresentados os objetivos da DCS e a pergunta norteadora da PA: "Como é tomar os remédios sempre, todos os dias, o dia todo?"; 3) culminou com a PA em si, onde cada adolescente fez o seu desenho a fim responder a pergunta; 4) cada adolescente apresentou sua PA e se desenvolveu a discussão; 5) consistiu na síntese e validação coletiva dos resultados.

Foi desenvolvida a transcrição dos diálogos gerados em grupo a partir da produção artística e, posteriormente, a análise de conteúdo dos dados, a qual se subdivide em três etapas: 1) préanálise, 2) exploração do material e 3) tratamento dos resultados obtidos. Na pré-análise, partindo dos documentos provenientes da transcrição da dinâmica, realizou-se a leitura exaustiva do material. Depois foram determinadas as unidades de registro, as quais são compostas por palavras-chave ou frases que se caracterizam como ideias centrais dos depoimentos dos participantes. ${ }^{9}$

$\mathrm{Na}$ exploração do material, foram identificadas por destaque cromático (legenda de cores) expressões no texto transcrito do encontro grupal, as quais culminassem em núcleos de compreensão. Essas expressões compuseram as categorias do estudo a serem interpretadas. Por fim, no tratamento dos resultados obtidos, desenvolveram-se a interpretação e a inter-relação dos dados empíricos com as bases teóricas disponíveis na literatura científica que corroboraram com a temática. 


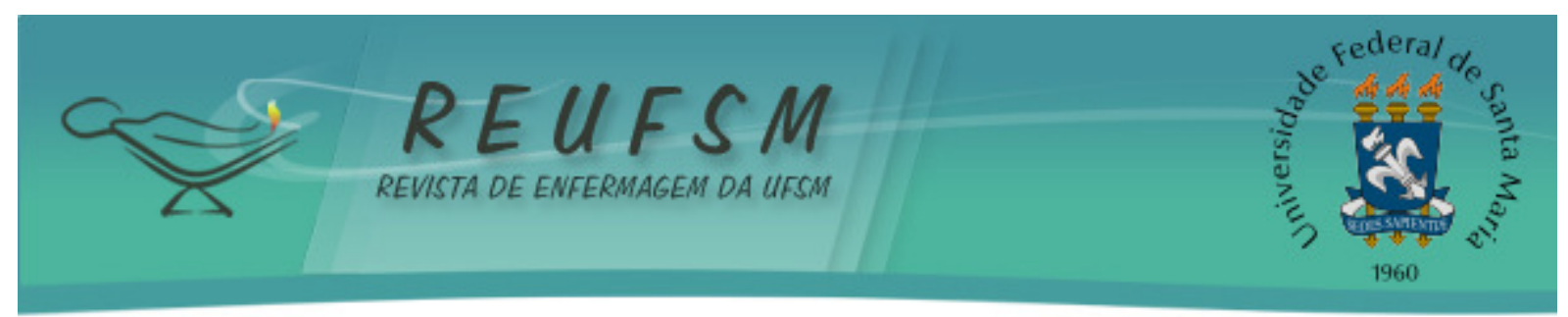

\section{RESULTADOS E DISCUSSÃO}

Emergiram quatro núcleos temáticos: da revolta à aceitação do diagnóstico e do tratamento; entendimento dos motivos do tratamento; querer fazer o tratamento e receber ajuda; dificuldades de seguir a rotina de ingerir medicamento sempre, o dia todo e todos os dias.

Os adolescentes expressaram que o processo de aceitação da condição sorológica se inicia com sentimentos de revolta e tristeza. Questionavam-se sobre os motivos de a infecção ter acontecido com eles, compreendendo a doença como algo ruim em sua vida. Com o tempo, passaram a entender a situação do diagnóstico e aceitar fazer o tratamento, a partir do diálogo com os familiares e com os profissionais de saúde. Esse processo de aceitação é representado pela produção artística de A2 (Figura 1).

Qualquer um às vezes pode pensar: por que será? Por que eu tenho que tomar remédio? Por que comigo? (A1)

Tem tanta gente, por que tinha que ter sido eu? Daí ficava triste [dia chuvoso, no caso a chuva era as minhas lágrimas]. Com o passar do tempo, eu fui observando e entendendo, aí fiquei mais ou menos [céu nublado que fica um pouco triste e um pouco feliz]. Daí hoje eu compreendi que eu tinha que fazer o tratamento, que era pro meu bem, pro meu bem-estar [céu ensolarado]. [...] revoltada, não queria tomar o remédio, não queria fazer o tratamento, não queria vir aqui. Daí os meus pais foram conversando comigo e eu fui entendendo, fui aceitando. (A2)

Uma nuvem escura em cima da gente: o HIV, a doença. (A6)

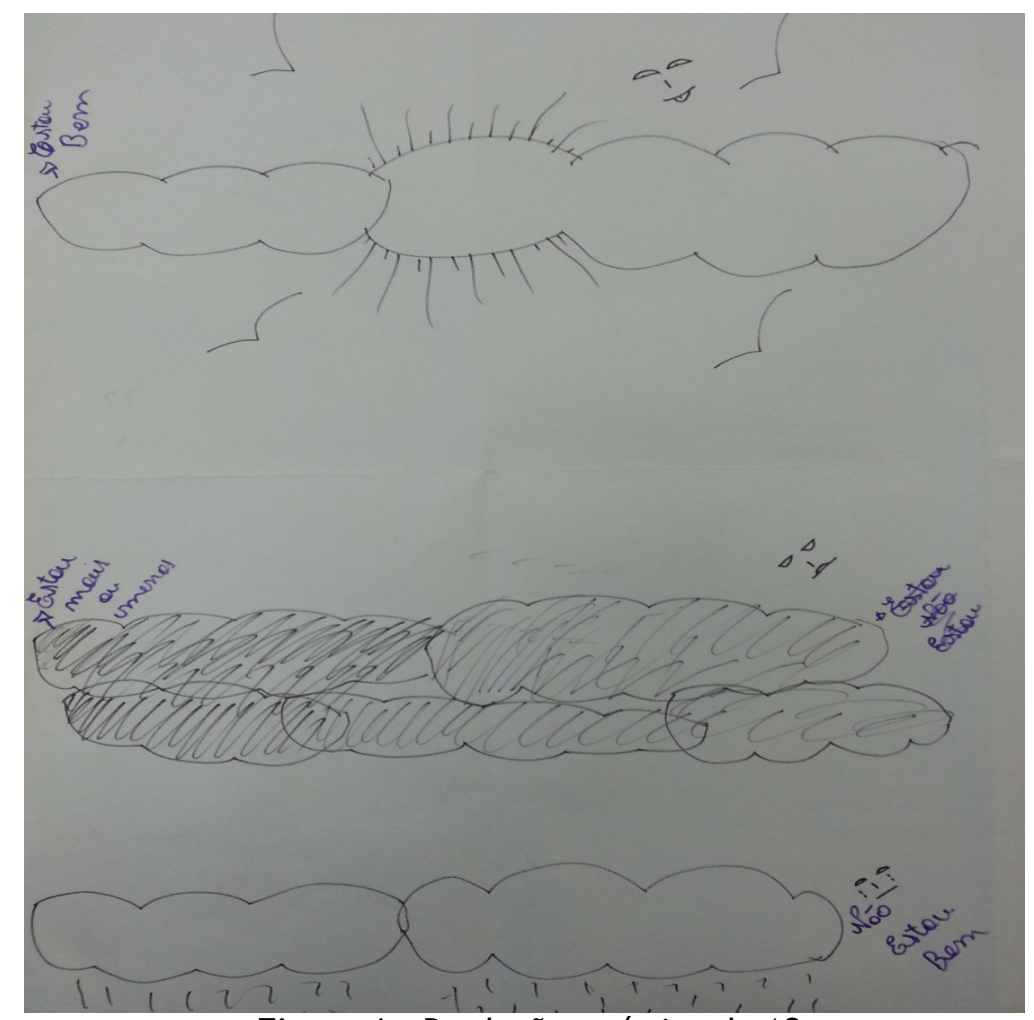

Figura 1 - Produção artística de A2. 


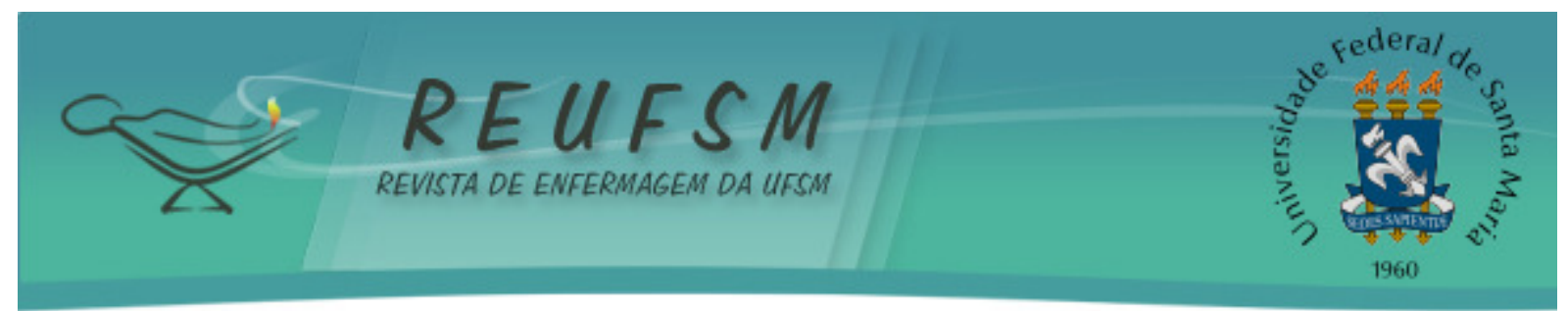

Para aceitar a condição crônica e a necessidade de tratamento, os adolescentes revelaram a importância do diálogo com familiares e profissionais de saúde. Discute-se a implicação da revelação do diagnóstico na compreensão da condição sorológica. Assim, interliga-se à adesão ao tratamento, quando o desconhecimento da condição sorológica ou os desdobramentos da mesma, como revolta e tristeza, são fatores que influenciam no cotidiano medicamentoso. ${ }^{10}$

A revelação do diagnóstico deve ser entendida como um processo que começa na infância, quando a infecção for por transmissão vertical do HIV, de acordo com o desenvolvimento cognitivo da faixa etária. Esse processo inicia-se por meio de explicações e esclarecimentos da necessidade de tomar medicamento diariamente, pela condição de saúde, e pode ser construído com um maior número de informações em diversas conversas. ${ }^{11}$

Os desafios da adesão são observados com maior frequência em adolescentes do que em crianças, uma vez que eles experienciam questionamentos e sentimentos de rebeldia diante do HIV. ${ }^{10}$ Reconhece-se a adesão como a prática comportamental resultante de um acordo entre a pessoa e a equipe de saúde. ${ }^{12}$ Assim, tem-se a negociação entre usuário e profissional de saúde como um fator importante na adesão, enfatizando a importância do processo de revelação do diagnóstico na promoção do diálogo e autonomia do adolescente no cuidado de si. ${ }^{10}$

Os adolescentes revelaram entender os motivos de manter o tratamento, que está relacionado ao seu bem-estar, visto que os medicamentos auxiliam o organismo a controlar a doença e evitar outros problemas de saúde. Então, têm que ingerir os medicamentos, mas, se não considerassem o tratamento importante, não o fariam. Sentiam-se bem enquanto estavam conseguindo mantê-lo conforme o prescrito, quase como se não tivessem a doença. Dependem disso para alcançar a possibilidade de ser e ter o que almejam na vida.

\section{É bom para o organismo não ter mais doenças. (A3)}

Se não fosse importante, eu não tomaria [...] é importante, pra poder ter uma vida normal que nem as outras pessoas, pra depois não ter outros problemas. [...] daí a gente tem mais saúde [...] posso ter uma vida normal [...] a gente depende dos remédios [...] porque tomando os remédios eu vou conseguir tudo que eu quero, eu vou ser mais [...] vou ter mais tempo de vida [...] adoecer, parar no hospital [...] o bom é que ajuda bastante no meu problema. (A7)

Tem que tomar, pra ficar melhor, não adoecer [...] eu tô tomando porque não quero ficar no hospital [...] pra ser o que eu quero ser na vida. (A8)

Quanto a entender os motivos de manter o tratamento, os adolescentes, quando sabem dos benefícios da medicação para o controle da doença e para a melhora da qualidade de vida, têm um comportamento de adesão ao tratamento. Para os adolescentes, a adesão é uma forma de sobreviver ao HIV e viver melhor, pois a eficácia do tratamento repercute na redução da morbimortalidade. A importância do tratamento e da adesão medicamentosa deve ser vista como adesão à vida. ${ }^{13}$

Os adolescentes apontaram a necessidade de querer fazer o tratamento e receber ajuda. Apesar de complicado e de exigir comprometimento e ajuda, quando conseguem cumpri-lo se sentem satisfeitos e veem os resultados como uma vitória diante das dificuldades. Para isso, é importante contar com ajuda dos familiares e dos profissionais de saúde.

Cada vez que eu tomo o remédio, é como se eu tivesse ocupando mais um espaço, vencendo a batalha contra o meu organismo. [...] 


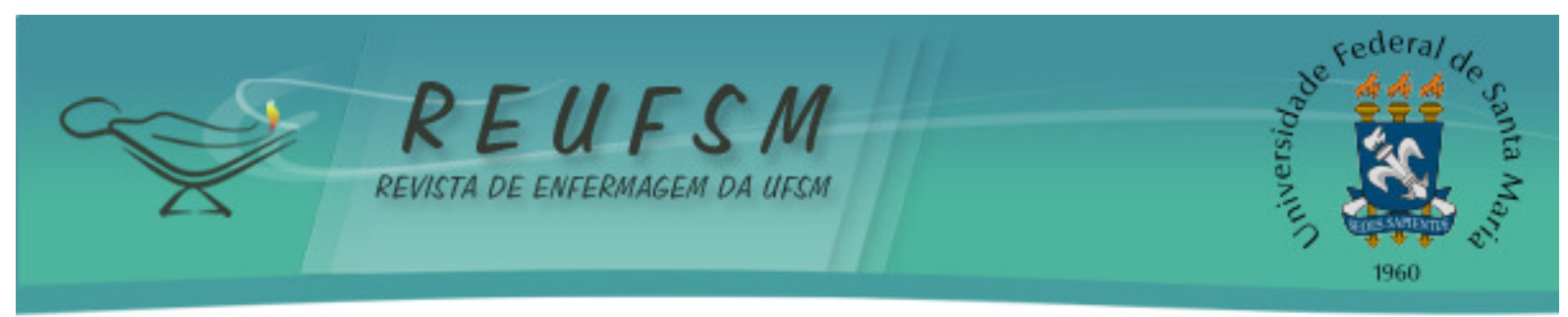

Satisfeita porque quem tá vencendo seria o meu comprometimento, e não a doença, que se eu tomar o remédio eu vou ficar melhor, então é isso que fico satisfeita. [...] É como se fosse um jogo de videogame, cada nível que a gente vai ganhando, a gente fica mais contente, e a cada nível também há seu grau de dificuldade, pode ser que não haja dificuldade, mas também é ótimo quando a gente ganha, a gente passou de um grau daquele difícil de dificuldade. Então, pra mim é ótimo. [...] Muitas pessoas acham que estão à beira da morte e eu não acho isso, é bom não ter medo da doença e estar vencendo ela aos poucos. (A1)

Fácil [tomar os remédios] é só querer [...] É querer se tratar, é querer cuidar da saúde, se não quiser não tem jeito, mas se tu quiser. Quero cuidar da minha saúde. (A4)

Eu quero tomar porque eu posso ficar tranquila de não ficar doente [...] até a mãe gritar, aí eu tomo. (A5)

Eu só tomo quando eu quero [...] Antes eu não gostava de tomar os remédios, eu tomava lá de vez em quando, eu não queria [...] Minha irmã me dá o remédio [...] ela me chama, aí eu não vou, tem horas que eu não vou [...] tô tomando porque minha irmã sempre me explica, daí eu vou lá e tomo. (A8)

Quanto a querer fazer o tratamento, os adolescentes precisam compreender os benefícios e ter consciência de que a não ingestão dos medicamentos pode agravar a sua situação de saúde. Essa compreensão, aliada à vontade de viver e ter planos futuros são fatores facilitadores da adesão. $O$ aconselhamento pode ajudar nesse processo por meio da compreensão da doença e do tratamento. ${ }^{13}$

Quanto à necessidade de ajuda para manter o tratamento medicamentoso, sabese que, quando os adolescentes não conhecem o seu diagnóstico, diminuem-se as possibilidades para que usufruam de apoio social, dificultando o acesso a recursos psicossociais fundamentais para o ajustamento à enfermidade. Negociar com esses adolescentes acerca do compromisso com o seu tratamento, o envolvimento e participação da família e amigos no tratamento e a criação de grupos de discussão auxilia para a adesão. $^{10}$

A efetividade do tratamento se faz para além da adesão do próprio adolescente, inclui o apoio, especialmente, do cuidador. Os cuidadores se deparam com desafios e a literatura tem apontado que, quanto maior o conhecimento sobre as implicações do diagnóstico e do tratamento, os cuidadores têm maiores chances de desenvolver habilidades efetivas que ajudam o adolescente na adesão ao tratamento. ${ }^{14}$

Os adolescentes relataram as dificuldades de seguir a rotina de ingerir medicamento sempre, o dia todo e todos os dias. Indicaram que é difícil de engolir os medicamentos, devido às características físicas e à palatabilidade. A questão do horário da medicação foi frisada pelos adolescentes (Figura 2). Os efeitos colaterais também influenciam negativamente na ingestão contínua.

Os remédios são grandes e quando a gente fica muito tempo com eles na boca solta o gosto [...] eu já tomo o remédio tranquilamente, não vomito, que antes eu vomitava. (A2) 


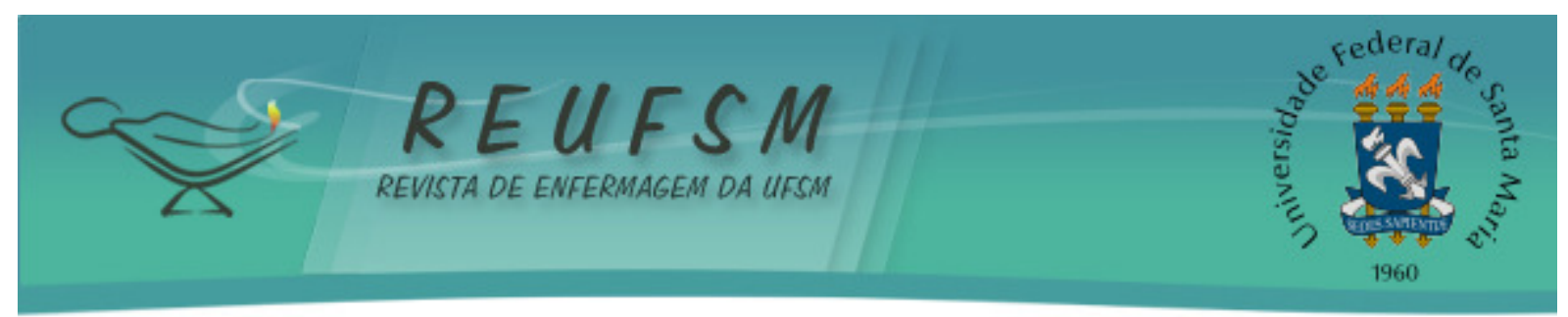

Eu tomo o remédio, ao meio-dia e à meia-noite [...] (A4)

Tomar o remédio todo dia [...] Eu falhava [...] não tavam fazendo efeito, nunca baixavam [...] [agora] eu tomo sempre, sempre eu tomo, até agora eu não parei de tomar [...] São muitos remédios que já tomei [...] Se não tomar o remédio pode criar uma resistência e complicar. (A6)

Tem que tomar sempre [...] Tem que tomar todo dia [...] Eu tomo certinho meus remédios, sem falhar [...] Eu não gosto do gosto, quase não tem gosto, mas não sei, tem um gosto estranho, diferente [...] é ruim tomar remédio [...] é chato. (A7)

Eu tomo [remédio], levanto, me arrumo e vou pra escola. Aí chega a noite, me dá preguiça de levantar e tomar [...]. (A8)

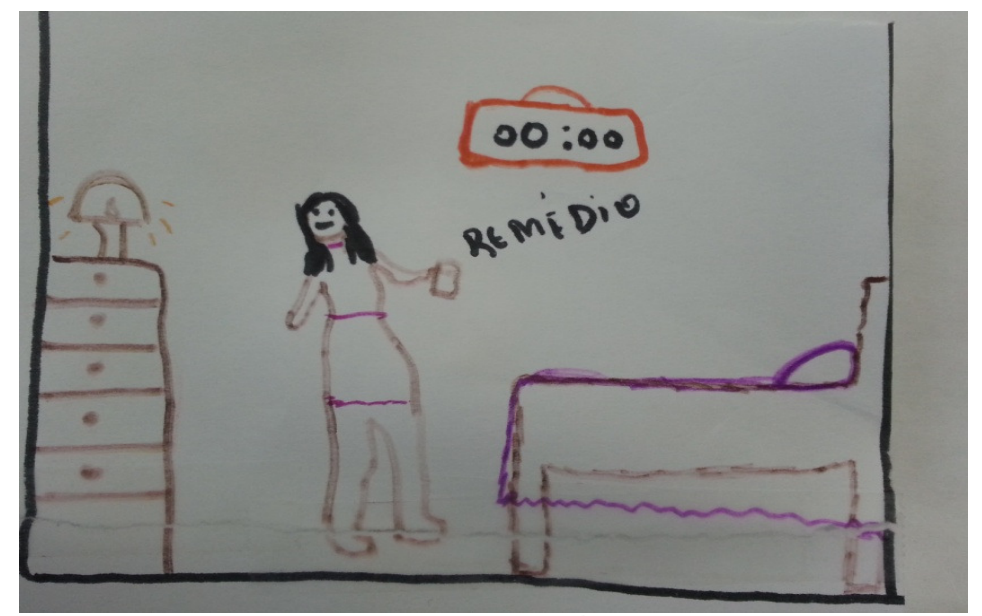

Figura 2 - Produção artística de A4.

Quanto às dificuldades de seguir o tratamento, os adolescentes acham difícil tomar os antirretrovirais devido à rotina que os permeia. Fatores como a quantidade, reações adversas, necessidade de períodos de jejum, incompatibilidade entre os medicamentos, dificuldade na compreensão das metas da terapia e da implicação do uso inadequado contribuem para comprometer o processo terapêutico. ${ }^{6,13,15}$

Destaca-se a influência das características físicas do medicamento, como o gosto, tamanho e cheiro, uma vez que o gosto desagradável emerge em outros estudos como dificultador na negociação entre cuidador e adolescente para a adesão ao tratamento. ${ }^{6,16}$ Os horários prescritos dos medicamentos interferem nos comportamentos dos adolescentes, por exemplo, quando devem ingeri-los nas primeiras horas da manhã ou fora do ambiente doméstico, como na escola. Pode haver resistência à ingestão da medicação, muitas vezes, por não compreenderem a necessidade de tratamento permanente e a repercussão da não adesão na sua saúde. ${ }^{6,12}$

Além disso, há manifestação de efeitos colaterais aos antirretrovirais, de modo que o tratamento constitua uma condição aversiva influenciando negativamente na ingestão contínua. ${ }^{17} \mathrm{~A}$ interrupção decorrente do incômodo causado por esses efeitos, somada ao grande volume dos comprimidos, aos horários de utilização e ao sabor desagradável estão associados diretamente à adesão à terapêutica. ${ }^{6,15}$ A dificuldade de adaptação devido aos efeitos colaterais pode necessitar de ajustes da TARV para evitar a interrupção no tratamento e as consequentes implicações no cuidado com sua saúde. ${ }^{18}$ 


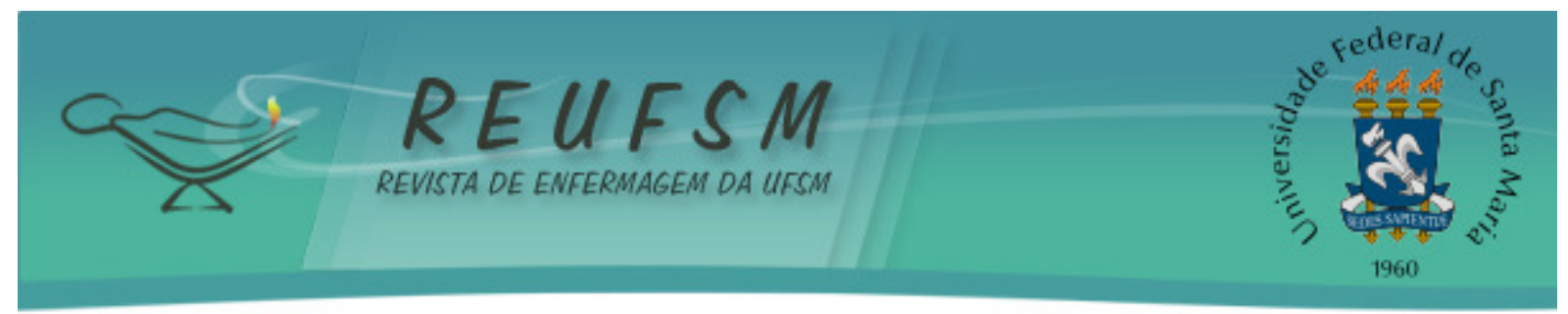

CONCLUSÃO

Conclui-se pela importância de conhecer o cotidiano vivenciado pelos próprios adolescentes infectados pelo HIV para manter o tratamento, visto que a adesão é determinante para o sucesso terapêutico, a fim de reduzir índices de morbidade e mortalidade por AIDS.

Aponta-se a importância de desenvolver estratégias de educação em saúde e de apoio, promovidas pelo cuidado de enfermagem durante 0 acompanhamento interdisciplinar de saúde, vislumbrando a autonomia do adolescente para o cuidado de si. Essas estratégias precisam contemplar o acompanhamento da revelação do diagnóstico e suas repercussões no dia a dia; o esclarecimento das dúvidas acerca da doença e do tratamento; a corresponsabilização pelo tratamento para que o adolescente saiba com quem pode contar para manter o tratamento; e os possíveis ajustes da prescrição medicamentosa ao cotidiano de cada adolescente, a fim de potencializar a adesão.

0 uso da DCS se mostrou um método eficiente para a produção de dados, uma vez que favorece a produção de dados de pesquisa qualitativa e o vínculo entre adolescente e pesquisador. Entretanto, consideraram-se desafios ao desenvolvê-la: a dificuldade de acessar e de reunir os adolescentes que atendiam os critérios de inclusão em grupo em um mesmo dia de atendimento no serviço de saúde; a interrupção da DCS devido ao funcionamento do serviço; e a complexidade da população adolescente em questões que envolvem a expressão de suas vivências em grupos diferentes aos do seu convívio. No entanto, eles foram superados por meio do apoio da equipe do serviço de saúde e dos pares na dinâmica de grupo.

\section{REFERÊNCIAS}

1. Brasil. Ministério da Saúde. Secretária de Vigilância em saúde. Departamento de DST, Aids e Hepatites Virais. Boletim Epidemiológico Aids/DST. 2011. Disponível em: http://www.aids.gov.br/sites/default/files/anexos/publicacao/2011/50652/boletim_aids_ 2011_final_m_pdf_26659.pdf.

2. Padoin SMM, Paula CC. Programa AIDS, educação e cidadania: perspectivas para a segunda década de extensão. Saúde (Santa Maria) [Internet]. 2012 [acesso em 2013 set 20];38(1):83-92. Disponível em: http://cascavel.ufsm.br/revistas/ojs2.2.2/index.php/revistasaude/article/view/3796/3357.

3. Senna SRCM, Dessen MA. Contribuições das teorias do desenvolvimento humano para a concepção contemporânea da adolescência. Psicol Teor Pesqui. 2012 jan/mar;28(1):101-8.

4. Paula CC, Padoin SMM. Cuidado de enfermagem ao adolescente com HIV/AIDS. PROENF. Programa de Atualização. 2013;7(4):109-50.

5. Dias AM, Cunha M, Santos AMM, Neves APG, Pinto AFC, Silva ASA, et al. Adesão ao regime terapêutico na doença crónica: revisão da literatura. Millenium. 2011;40:201-19.

6. Paula CC, Padoin SMM, Silva CB, Magnago TSBS, Valadão MC, Langendorf TF. Factors associated to the non-adherence to antiretroviral therapy of adolescents with HIV/AIDS. Rev Enferm UFPE on line[Internet]. 2012 set [acesso em 2013 jun 10];6(9):2196-203. Disponível em: http://www.revista.ufpe.br/revistaenfermagem/index.php/revista/article/view/3263/pdf_1463.

\section{Brasil. Ministério da Saúde. Conselho Nacional de Saúde. Comissão Nacional de Ética em}

Pesquisa. Normas para pesquisa envolvendo seres humanos (Res. CNS $n^{\circ} 196 / 96$ e outras). $2^{\mathrm{a}}$ ed. ampl, $1^{\mathrm{a}}$ reimpressão. Brasília (DF): Ministério da Saúde; 2003. 64 p. (Série E. Legislação de Saúde). 


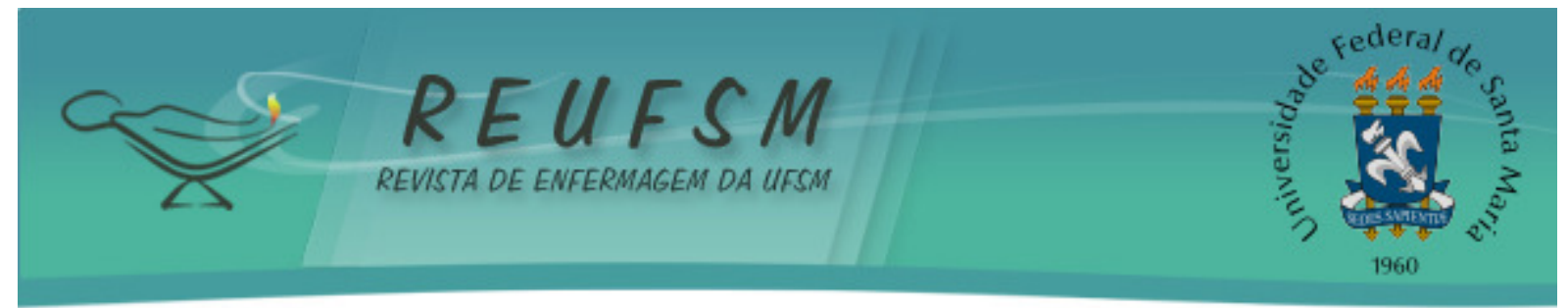

8. Cabral IE. Aliança de saberes no cuidado e estimulação da criança bebê: concepções de estudantes e mães no espaço acadêmico de enfermagem [tese]. Rio de Janeiro: UFRJ, Escola de Enfermagem Anna Nery;1997. 210 p.

9. Minayo MCS. O desafio do conhecimento: pesquisa qualitativa em saúde. $11^{\text {a }}$ ed. São Paulo: Hucitec; 2008.

10. Guerra CPP, Seidl EMF. Crianças e adolescentes com HIV/aids: revisão de estudos sobre revelação do diagnóstico, adesão e estigma. Paidéia. 2009 jan/abr;19(42):59-65.

11. Bennett Murphy LM, Flowers S, McNamara KA, Young-Saleme T. Fathers of children with cancer: involvement, coping, and adjustment. J Pediatr Health Care. 2008;22(3):182-9.

12. Brasil. Ministério da Saúde. Secretaria de Vigilância em Saúde. Programa Nacional de DST e Aids. Manual de rotinas para assistência de adolescentes vivendo com HIV/Aids. Brasília (DF): Ministério da Saúde, 2006. 176 p. (Série Manuais; $n^{\circ}$ 69).

13. Kourrouski MFC, Lima RAG. Adesão ao tratamento: vivências de adolescentes com HIV/AIDS. Rev Latinoam Enferm. 2009;17(6):947-52.

14. Salles CMB, Ferreira EAP, Seidl EMF. Adesão ao tratamento por cuidadores de crianças e adolescentes soropositivos para o HIV. Psicol Teor Pesqui. 2011 out/dez;27(4):499-506.

15. Feitosa AC, Lima HJA, Caetano JA, Andrade LM, Beserra EP. Terapia anti-retroviral: fatores que interferem na adesão de crianças com HIV/AIDS. Esc Anna Nery Rev Enferm. 2008 set;12(3):515-21.

16. Campbell C, Skovdal M, Mupambireyi Z, Madanhire C, Nyamukapa C, Gregson S. Building adherence-competentcommunities: factors promoting children's adherence to anti-retroviral HIV/AIDS treatment in rural Zimbabwe. Health \& Place. 2012 mar;18(2):123-31.

17. Padoin SMM, Paula CC, Hoffmann IC, Valadão MC, Rodrigues AP, Langendorf TF. Alimentação de crianças que convivem com a AIDS: vivências de familiares/cuidadores em atividade grupal. Rev Enferm UFSM [Internet]. 2012 jan/abr [acesso em 2013 jun 3];2(1):213-21. Disponível em: http://cascavel.ufsm.br/revistas/ojs-

2.2.2/index.php/reufsm/article/view/2804/3146.

18. Paula CC, Cabral IE, Souza IEO. O cotidiano de crianças infectadas pelo HIV no adolescer: compromissos e possibilidades do cuidado de si. DST J Bras Doenças Sex Transm [Internet]. 2008 [acesso em 2013 jun 3];20(3-4):173-8. Disponível em: http://www.dst.uff.br/revista20-3-42008/3-0-cotidiano-de-criancas-JBDST-20-3-4-2008.pdf.

Data de recebimento: $14 / 07 / 2013$

Data de aceite: $24 / 10 / 2013$

Contato com autor responsável: Cristiane Cardoso de Paula

Endereço postal: Av. Roraima, Cidade Universitária, $n^{\circ} 1000$, Centro de Ciências da Saúde prédio 26, $3^{\circ}$ andar, sala 1336. Santa Maria/Rio Grande do Sul, Brasil. CEP: 97105-900.

E-mail: cris_depaula1@hotmail.com 